\title{
Prenatal diagnosis, associated findings and postnatal outcome of fetuses with truncus arteriosus communis (TAC)
}

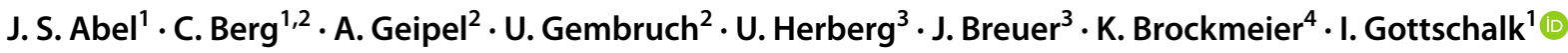

Received: 12 November 2020 / Accepted: 9 April 2021 / Published online: 24 May 2021

(c) The Author(s) 2021

\begin{abstract}
Purpose To assess the spectrum of associated anomalies, the intrauterine course, postnatal outcome and management of fetuses with truncus arteriosus communis (TAC)

Methods All cases of TAC diagnosed prenatally over a period of 8 years were retrospectively collected in two tertiary referral centers. All additional prenatal findings were assessed and correlated with the outcome. The accuracy of prenatal diagnosis was assessed.

Results Thirty nine cases of TAC were diagnosed prenatally. Mean gestational age at first diagnosis was 22 weeks (range 13-38). Two cases were lost follow-up. Correct prenatal diagnosis of TAC was made in $87.5 \%$ and of TAC subtype in 90.5\%. Prenatal diagnosis was incorrect in three cases: one newborn had aortic atresia with ventricular septal defect (VSD) postnatally, one had hypo-plastic right ventricle with dextro transposition of the great arteries (d-TGA) with coarctation of the aorta and a third newborn had tetralogy of fallot (TOF) with abnormal origin of the left pulmonary artery arising from the ascending aorta postnatally. These 3 cases were excluded from further analysis.

In $26.5 \%$ of cases, TAC was an isolated finding. $38.2 \%$ of fetuses had additional chromosomal anomalies. Among them, microdeletion 22q11.2 was most common with a prevalence of $17.6 \%$ in our cohort. Another 3 fetuses were highly suspicious for non-chromosomal genetic syndromes due to their additional extra-cardiac anomalies, but molecular diagnosis could not be provided. Major cardiac and extra-cardiac anomalies occurred in between $8.8 \%$ and 58.8\%, respectively. Predominantly, extra-cardiac anomalies occurred in association with chromosomal anomalies. Additionally, severe IUGR occurred in 17.6\%. There were 14 terminations of pregnancy (41.2\%), 1 (2.9\%) intrauterine fetal death, 5 postnatal deaths (14.7\%) and 14 (41.2\%) infants were alive at last follow-up. Intention-to-treat survival rate was $70 \%$. Mean follow-up among survivors was 42 months (range 6-104). Postoperative health status among survivors was excellent in $78.6 \%$, but $46.2 \%$ needed repeated re-interventions due to recurrent pulmonary artery or conduit stenosis. The other $21.4 \%$ of survivors were significantly impaired due to non-cardiac problems.

Conclusion Truncus arteriosus communis is a rare and complex cardiac anomaly that can be diagnosed prenatally with high precision. TAC is frequently associated with chromosomal and extra-cardiac anomalies, leading to a high intrauterine and postnatal loss rate due to terminations and perioperative mortality. Without severe extra-cardiac anomalies, postoperative health status is excellent, independent of the subtype of TAC, but the prevalence of repeated interventions due to recurrent stenosis is high.
\end{abstract}

Keywords Truncus arteriosus communis · Common arterial trunk · TAC - Aortopulmonary trunk · Congenital heart defect . Fetus $\cdot$ Prenatal diagnosis

\section{Introduction}

Truncus arteriosus communis (TAC) is a rare conotruncal anomaly, representing $1.6 \%$ of all newborns with congenital heart disease [1] and 1.07 of 10.000 live births [2, 3]. It is

I. Gottschalk

ingo.gottschalk@uk-koeln.de

Extended author information available on the last page of the article found more commonly in offspring of diabetic mothers [4]. 
Truncus arteriosus communis is characterized by a single (common) arterial trunk that exits the heart by the way of a single (common) arterial valve and gives rise directly to the coronary, systemic and one or both pulmonary arteries $[5,6]$. While aorta and main pulmonary artery (MPA) originate from a common root, failure during the process of separation leads to a persistent common arterial trunk with a common truncal valve with four or more leaflets [7]. This common truncal valve can either be stenotic or insufficient [8]. Frequently, TAC is accompanied by a large ventricular septal defect (VSD) [9] with overriding of the large common arterial trunk.

Two commonly used classifications of TAC describe (1) the different anatomy of the pulmonary arteries which may either arise from a MPA or as direct branches of the aortic arch or the descending aorta and (2) additional aortic arch anomalies. As Collet and Edwards classified the TAC exclusively according to the anatomic origin of the pulmonary arteries and to the spatial relationship between these vessels [10], Van Praagh proposed another anatomical classification which also takes additional aortic arch anomalies into account [11]. As both classification systems have a substantial overlap, we reviewed both classification systems and grouped our cohort into three TAC types according to clinical and surgical aspects and based on both Collet and Edwards and Van Praagh classification.

Because systemic, pulmonary and coronary blood flow are supplied by one common vessel neonates can present with a wide spectrum of clinical features of congestive heart failure depending on the high volume of pulmonary blood flow and the presence or absence of truncal valve insufficiency. As TAC is a cyanotic cardiac anomaly characterized by increased pulmonary blood flow, early surgical repair in the neonatal period may prevent the long-term sequelae of pulmonary over-circulation and heart failure [12-18]. Therefore, precise prenatal echocardiographic diagnosis is mandatory for counselling parents with regard to prognosis and treatment options as well as planning for delivery and postnatal surgical management of the fetuses with TAC.

Indeed, in prenatal situation, it may be difficult to distinguish TAC from other conotruncal malformations namely tetralogy of fallot (TOF) and pulmonal atresia (PA) as both also have a VSD and an overriding aorta.

The components of surgical complete cardiac repair consist of (a) closure of the VSD, (b) right-ventricle-to-pulmonary-artery (RV-PA) conduit and, if necessary, reconstruction of the left ventricular outflow tract in TAC type A4 with hypo-plastic or interrupted aortic arch. Due to pulmonary overflow postnatally, a banding of the pulmonary arteries is frequently performed prior to complete repair. During childhood, re-interventions like dilatation or stenting of the PA or exchange of the RV-PA conduit will frequently be necessary due to recurrent stenoses of PA or insufficiencies of the conduit valve. Additional cardiac and especially extracardiac and chromosomal anomalies occur quite frequently and may complicate the surgical course.

The aim of this study was to assess the spectrum of associated cardiac, extra-cardiac and chromosomal anomalies, the intrauterine course and postnatal outcome of fetuses with TAC.

\section{Methods}

All prenatally diagnosed cases of TAC were retrospectively reviewed for intrauterine course and outcome in the perinatal database of two tertiary referral centers for prenatal medicine and fetal echocardiography (University of Cologne and University of Bonn, Germany). All fetuses with TAC were diagnosed between January 2010 and December 2018.

The anatomic survey and fetal echocardiography were performed in a standardized fashion. Fetal echocardiography was carried out by a segmental approach using standardized anatomical planes incorporating pulsed-wave and color Doppler imaging [19, 20]. $5 \mathrm{MHz}, 7.5 \mathrm{MHz}$ or $9 \mathrm{MHz}$ sector or curved array-probes were used for all ultrasound examinations (ATL HDI 5000 and IU22 Philips, Hamburg, Germany; Voluson 730 Pro and Expert, E8 and E10, respectively, GE Healthcare, Solingen, Germany). A pediatric cardiologist attended at least one of the prenatal ultrasound examinations and subsequently counselled the patients. Following delivery and initial care by the attending neonatologist, all newborns were examined by a pediatric cardiologist within $12 \mathrm{~h}$ after birth. Conventional karyotyping was performed in all cases, predominantly prenatally, otherwise postnatally.

Prenatally, we distinguished three different TAC types based on both Collet and Edwards' and Van Praagh's classification, as both classification systems have a substantial overlap and both were used inconsistently in pediatric and cardio-surgical literature:

- Type 1 corresponds to both Collet and Edwards' and Van Praagh's type 1 and included all cases of TAC with an existing MPA.

- Type 2 combined Collet and Edwards' type 2 and 3, which corresponds to Van Praagh's type 2 and included all TAC with a separate branching of the pulmonary arteries, either close together or at some distance from each other, as prenatal differentiation between both Collet and Edwards' types is barely possible.

- Type A4 corresponds to Van Praagh's type A4 and included all TAC with aortic arch anomalies including hypo-plastic or interrupted aortic arch.

Additionally, we described any functional abnormality of the truncal valve as dysplastic, stenotic or insufficient, 
any major cardiac and extra-cardiac anomalies as well as any chromosomal or non-chromosomal syndromic anomalies. Minor anomalies like right aortic arch, persistent left superior vena cava, aberrant right subclavian artery and single umbilical artery were documented, but not classified as associated cardiac or extra-cardiac anomalies, respectively.

All cases were classified according to pregnancy outcome into five groups: termination of pregnancy (TOP), intrauterine fetal (IUFD) or neonatal death (NND), death in infancy or childhood (CHD) and survivors. Neonatal death was defined as death within the first 28 days of live, CHD as any death after 28 days of live. Postnatal medical files of echocardiography, cardiac catheterization, surgery or autopsy were available for confirmation of the prenatal diagnosis in all live born children. Pre and postnatal diagnoses of all 22 live born children and 2 terminated pregnancies with postmortal autopsy were compared to assess the accuracy of prenatal diagnosis.

All data were retrieved from medical files, stored ultrasound images and, if available, from ultrasound video recordings. The following variables were assessed, as far as retrospectively achievable: maternal age, gestational age at first diagnosis, type of TAC, associated cardiac, extracardiac and chromosomal or non-chromosomal genetic anomalies.

Pregnancies with a postnatal diagnosis differing from TAC were excluded from further outcome analysis. Only for assessment of accuracy of prenatal diagnosis, these cases were included. Both cases, that were lost to follow-up, were also excluded from the study.

Intergroup comparisons were made using the chi-square test, Student's $t$ test or Fisher's exact test when appropriate.
Values are given as mean \pm SD unless otherwise indicated. $P<0.05$ was considered statistically significant. This retrospective study was approved by the local ethical committee of human research (No 20-1517).

\section{Results}

Truncus arteriosus communis was diagnosed in 39 fetuses during the study period (Fig. 1). Mean gestational age at first diagnosis was 22 weeks (range 13-38). In 8 cases diagnosis was made before 20 weeks of gestation.

Two cases were lost to follow-up and were excluded from further outcome analysis. Another 3 cases had an incorrect prenatal diagnosis and were also excluded from outcome analysis, but included for assessment of diagnostic accuracy. In the first case, initial prenatal echocardiography was performed not before 38 weeks of gestation and maternal body mass index (BMI) was 39. Postoperative diagnosis was Aortic Atresia with VSD instead of TAC. In the second case, first echocardiography was performed at 34 weeks and maternal BMI was 37. Postnatal diagnosis was Hypo-plastic Right Ventricle with d-TGA and Coarctation of Aorta. In the third case, the pregnant woman was only seen once at early 19 weeks and prenatal diagnosis of TAC type 1 was postnatally reclassified as Tetralogy of Fallot with abnormal origin of the left pulmonary artery arising from the ascending aorta.

The main reasons for referral in one of our two participating referral centers were either (a) suspicion of congenital heart disease due to an abnormal three vessel view or (b) presence of extra-cardiac anomalies in externally performed

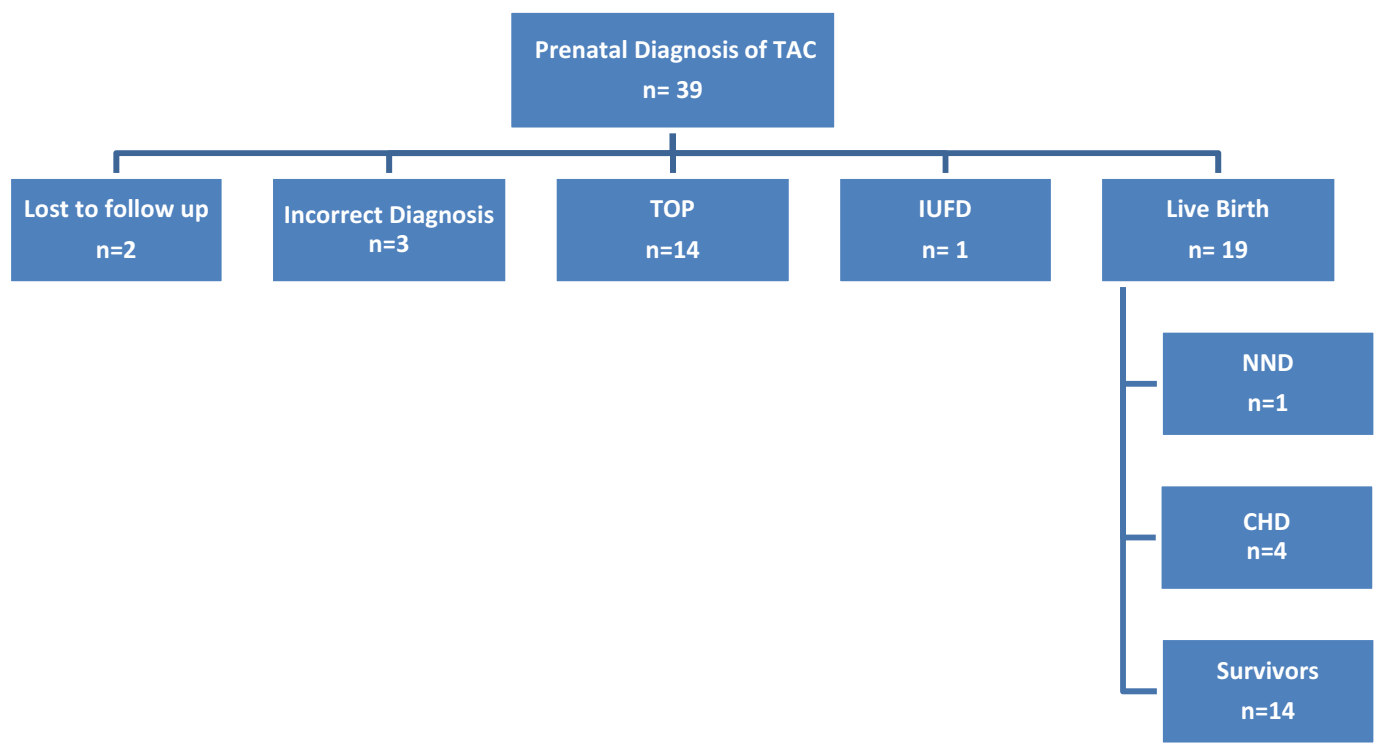

Fig. 1 Outcome of 39 cases with prenatally diagnosed TAC. TOP termination of pregnancy, IUFD intrauterine fetal death, NND neonatal death, CHD death in infancy or childhood 
ultrasound in between $41 \%$ and $44 \%$, respectively. In the latter, diagnosis of TAC was then made as an additional finding. In $15 \%$ of cases, diagnosis was made as (c) an incidental finding during routine first or second trimester anomaly scan in our two centers. Despite consistent improvement in fetal echocardiography during the last decade, there was no tendency towards an earlier diagnosis during the 8-year study period in our cohort.

\section{Additional genetic, cardiac and extra-cardiac anomalies}

After exclusion of cases with incorrect diagnosis and both cases that were lost to follow-up, 9 of our 34 fetuses (26.5\%) had isolated TAC. Chromosomal anomalies occurred in 13 fetuses with a prevalence of $38.2 \%$ (Table 1). Among them, microdeletion 22q11 was most common with a prevalence of $17.6 \%$ in our cohort. Due to their complex additional anomalies, another 3 fetuses were highly suspicious for

Table 1 All 34 cases with TAC according to additional anomalies and outcome

\begin{tabular}{|c|c|c|c|c|}
\hline No & Karyotype & Cardiac anomalies & Extra-cardiac anomalies & Outcome \\
\hline 1 & Microdeletion 22q11 & ARSA & Thymus aplasia & TOP \\
\hline 2 & Microdeletion 22q11 & ARSA & Thymus aplasia & TOP \\
\hline 3 & Microdeletion 22q11 & - & Hygroma colli & TOP \\
\hline 4 & Microdeletion 22q11 & - & Thymus aplasia, cerebellar hypoplasia, microcephaly, SUA & CHD \\
\hline 5 & Microdeletion 22q11 & - & Thymus aplasia, IUGR, SUA & CHD \\
\hline 6 & Microdeletion 22q11 & - & Thymus aplasia, SUA & Survivor \\
\hline 7 & 46, XY del(1) (q42.1) & - & Corpus callosum agenesis, Dandy-Walker malformation, retrognathia, SUA & TOP \\
\hline 8 & 46, XY del(2) (q31q32.2) & DORV, HLV & Hypertelorisma, syndactylia & TOP \\
\hline 9 & 46, XX del(9q34) & RAA, LPSVC & Thymus aplasia, cerebellar hypoplasia, microcephaly, SUA & TOP \\
\hline 10 & 46, XX der9 & - & - & TOP \\
\hline 11 & Trisomy 9 & - & Myelomeningocele & TOP \\
\hline 12 & Trisomy 13 & HLV & $\begin{array}{l}\text { Holoprosencephaly, proboscis, hypoterlorism, polydactylia both hands and } \\
\text { feet }\end{array}$ & TOP \\
\hline 13 & Trisomy 16 Mosaicism & - & Severe early IUGR & TOP \\
\hline 14 & $46, X^{*}$ & - & Uretro-pelvic junction obstruction, gall bladder aplasia, severe IUGR, SUA & TOP \\
\hline 15 & $46, \mathrm{XY}^{*}$ & - & Holoprosencephaly, medial lip and cleft palate, unilateral anophthalmia & TOP \\
\hline 16 & $46, X^{*}$ & RAA & $\begin{array}{l}\text { Retrognathia, cleft palate, clenched fingers, polydactyly, kyphoscoliosis, } \\
\text { micromelia }\end{array}$ & Survivor \\
\hline 17 & $46, \mathrm{XX}$ & - & Holoprosencephaly, hypotelorism, microcephaly & TOP \\
\hline 18 & 46, XY & - & Holoprosencephaly, severe IUGR & IUFD \\
\hline 19 & $46, X Y$ & - & Syringomyelia & Survivor \\
\hline 20 & 46, XY & RAA & Moderate hydronephrosis & Survivor \\
\hline 21 & 46, XX & - & Retrognathia, cleft palate & Survivor \\
\hline 22 & 46, XX & LPSVC, RAA & Left-sided diaphragmatic hernia, SUA & Survivor \\
\hline 23 & $46, X Y$ & - & Severe IUGR & $\mathrm{CHD}$ \\
\hline 24 & 46, XX & - & Severe IUGR & Survivor \\
\hline 25 & 46, XY & - & SUA & TOP \\
\hline 26 & 46, XY & RAA & SUA & NND \\
\hline 27 & 46, XY & AVSD, LPSVC, RAA & SUA & Survivor \\
\hline 28 & 46, XX & - & - & CHD \\
\hline 29 & $46, \mathrm{XX}$ & - & - & Survivor \\
\hline 30 & 46, XX & - & - & Survivor \\
\hline 31 & 46, XX & - & - & Survivor \\
\hline 32 & 46, XY & - & - & Survivor \\
\hline 33 & 46, XY & - & - & Survivor \\
\hline 34 & 46, XY & - & - & Survivor \\
\hline
\end{tabular}

$A R S A$ aberrant right subclavian artery, $R A A$ right aortic arch, $L P S V C$ left persistent superior vena cava, DORV double-outlet right ventricle, $H L V$ hypo-plastic left ventricle, AVSD atrio-ventricular septal defect, IUGR intrauterine growth restriction, SUA singular umbilical artery

*Highly suspicious for non-chromosomal genetic syndrome 
non-chromosomal genetic syndromes, but molecular diagnosis could not be provided. Invasive prenatal testing was performed in 25 pregnancies. Postnatally, none of the remaining newborns had additional chromosomal anomalies.

Additional major cardiac anomalies occurred only in 3 (8.8\%) cases and included hypo-plastic left ventricle, double-outlet right ventricle and atrio-ventricular septal defect (Table 1). Hypo-plastic or interrupted aortic arch was not described as additional cardiac defect, as it was classified as TAC type A4. Minor cardiac anomalies were right aortic arch (RAA), persistent left superior vena cava (LPSVC) and aberrant right subclavian artery (ARSA) in $6(17.6 \%)$, $4(11.7 \%)$ and $2(5.9 \%)$ cases, respectively.

Major extra-cardiac anomalies occurred in 20 (58.8\%) cases, including cerebellar hypoplasia, Dandy-Walker-Malformation, holoprosencephaly, facial clefts, myelomeningocele or syringomyelia, diaphragmatic hernia and corpus callosum agenesis (Table 1). Frequently, those anomalies were associated with additional chromosomal anomalies or with fetuses that were highly suspicious for non-chromosomal genetic syndromes. Severe IUGR occurred in another $6(17.6 \%)$ cases. Singular umbilical artery was classified as minor anomaly and was seen in $11(32.4 \%)$ fetuses.

The high prevalence of additional genetic and major extra-cardiac anomalies led to a high pre- and postnatal loss rates, mainly due to terminations of pregnancy and spontaneous demise in the early childhood, respectively.

\section{Outcome}

Termination of pregnancy (TOP) was opted in 14 of our $34(41.2 \%)$ cases (Fig. 1). All but one fetus had additional major anomalies including 10 fetuses with chromosomal anomalies.

Intrauterine fetal death (IUFD) at 21 weeks of gestation occurred in 1 fetus (2.9\%) with alobar holoprosencephaly and severe early intrauterine growth restriction (IUGR).

Nineteen (55.9\%) neonates with postnatally confirmed TAC were born alive. One (2.9\%) neonate died during neonatal period (NND) and $4(11.8 \%)$ infants in early childhood (CHD). The neonate had isolated TAC and died 5 days after completed cardiac repair due to multiorgan failure while he was treated with extra corporal membrane oxygenation (ECMO). The remaining 4 infants died within their first 3 months of life: one infant had microdeletion $22 q 11$ and died after pulmonal arterial (PA) banding due to intraventricular hemorrhage and right heart and renal failure. A 2nd infant with microdeletion $22 \mathrm{q} 11$ died after completed cardiac repair due to heart and renal failure while he was treated with a pacemaker and peritoneal dialyses simultaneously. A 3rd infant who was delivered severely growth restricted at 32nd week of gestation (birth weight $880 \mathrm{~g}$ ), underwent PA-banding and stenting of the persistent arterial duct and died at the age of 3 months due to prematurity and heart failure. The 4th infant developed necrotizing enterocolitis postnatally and underwent placement of a colostomy on her 10th day of life. During surgery, she had myocardial infarction with hypoxic brain damage and developed severe renal failure. She died at the age of 7 weeks after her parents opted for palliative care.

Fourteen children with confirmed TAC were alive at last follow-up, resulting in an overall survival rate of $41.2 \%$. After exclusion of TOP, the intention-to-treat survival rate was $70 \%$. Mean follow-up among survivors was 42 months (range 6-104).

\section{Postnatal cardiac surgery}

All survivors underwent cardio-surgical treatment. Due to initial pulmonary overflow postnatally, 11 of $19(57.9 \%)$ neonates needed initial banding of the pulmonary arteries prior to complete cardiac repair, 5 (26.3\%) of them received additional stenting of the arterial duct. Single-stage complete cardiac repair with patch-closure of the VSD and insertion of a right-ventricle-to-pulmonary-artery (RV-PA) bovine conduit were performed in $11(78.6 \%)$ infants, predominantly within their first weeks of life. Among them, 6 neonates needed additional reconstruction of their hypoplastic or interrupted aortic arch. Another 2 (14.3\%) infants with TAC type 1 suffered from progressive cyanosis after conduit insertion due to recurrent conduit stenosis and had to undergo additional Blalock-Taussig shunting and subsequent Glenn anastomosis. One (7.1\%) infant only had stenting of persistent arterial duct so far and is still awaiting complete repair.

After cardiac surgery, recurrent stenoses of the conduits or pulmonary arteries (PA) as well as insufficiencies of the valved conduits occurred frequently during childhood. Six (46.2\%) of the 13 infants who had achieved complete cardiac repair required 2-6 re-interventions (mean 3.3), either stenting or dilatation of PA. Among them, 2 (15.4\%) infants required additional conduit-exchange. Another infant (7.7\%) developed complete heart block and achieved a pacemaker.

Postoperative health status among our survivors was either excellent or significantly impaired. Eleven (78.6\%) infants had an excellent health status at last follow-up, although one of them reported on mildest cyanosis during intense physical activity and another one on first-grade heart insufficiency during intense activity. Indeed, the remaining 3 (21.4\%) infants are significantly impaired due to non-cardiac problems: one infant had retrognathia with cleft palate and suffered from dysphagia and impaired hearing. Another infant was affected by sepsis and necrotizing enterocolitis, needed tracheostoma for intermittent home ventilation and respiration therapy due to total atelectasis and severely suffered from seizure, 
psychomotor and mental retardation. The third, presumably syndromal infant with multiple extra-cardiac anomalies needed tracheostoma and suffered, among other problems, from severe pulmonary hypoplasia, hypertension and impaired hearing.

\section{TAC typing and accuracy of prenatal ultrasound}

To determine the TAC types, we included all cases with confirmed diagnosis of TAC, either by post-mortal autopsy $(n=2)$ or postnatal echocardiography and cardiac surgery $(n=19)$. The most common type was type $\mathbf{1}$ in $38.1 \%$, followed by type $\mathbf{A} \mathbf{4}$ in $33.3 \%$ and type $\mathbf{2}$ in $28.6 \%$ (Figs. 2, $3,4,5$ and 6 ). In $23.5 \%$, the common trunk valve was severely insufficient and/or stenotic.

To determine the accuracy of prenatal diagnosis, we included all cases with prenatally presumed diagnosis of TAC and confirmed postnatal diagnosis of congenital heart defect, either post-mortally by autopsy $(n=2)$ or postnatally by echocardiography $(n=22)$. Correct prenatal diagnosis of TAC was made in $21(87.5 \%)$ cases. Among them, exact TAC subtyping was correct in $19(90.5 \%)$ cases.

\section{Discussion}

Truncus arteriosus communis is a rare conotruncal anomaly which accounts for $1-2 \%$ of all congenital heart defects in newborns [1]. Prenatal incidence is higher due to a

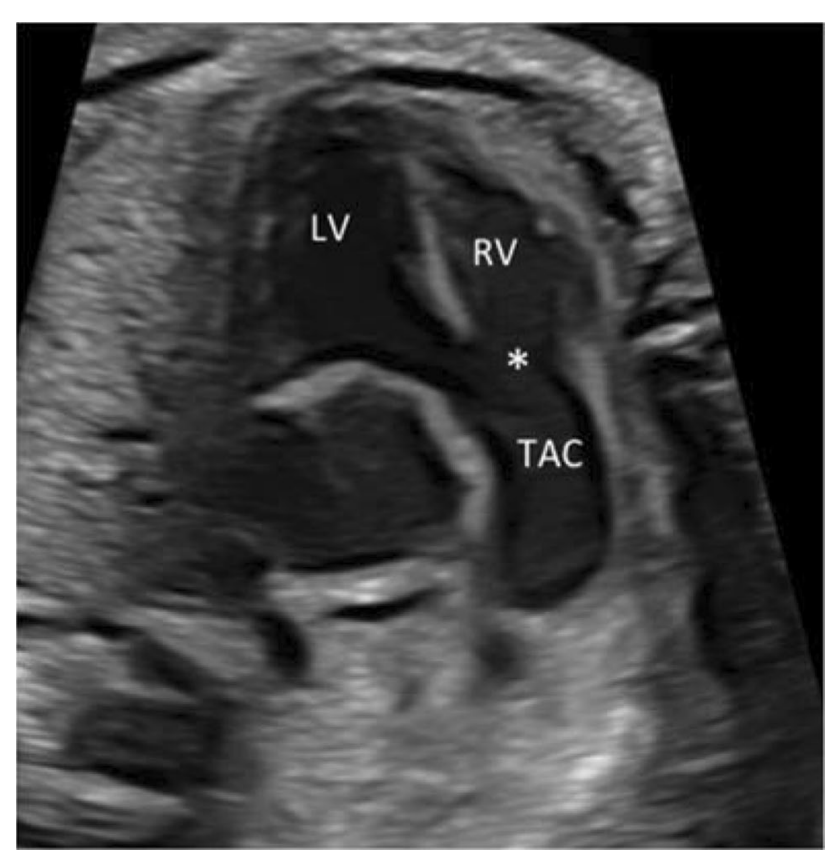

Fig. 2 Common arterial trunk (TAC) overriding a large VSD (*)

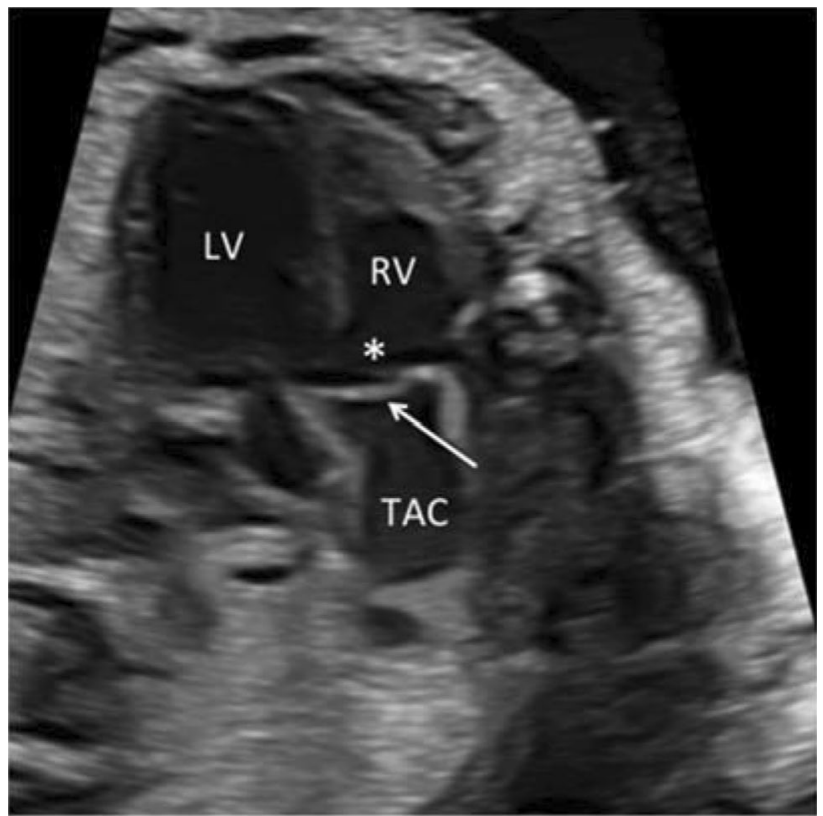

Fig. 3 Large common arterial trunk valve (arrow). $L V$ left ventricle, $R V$ right ventricle, $* \mathrm{VSD}$

significantly high prenatal loss rate [21]. As reported in literature $[11,22]$, both sexes in our cohort were equally affected with $52.4 \%$ of affected male and $47.6 \%$ of affected female fetuses.

Due to the rarity of the disease, previously published studies on prenatally diagnosed TAC described either extremely small cohorts with only very short postnatal follow-up periods of less than a year [21, 23-25] or included prenatally as well as postnatally diagnosed cases of TAC without any information about additional anomalies and type of surgical treatment [26]. In addition, the numbers of survivors in those series were extremely small, due to the high prevalence of terminations of pregnancy, intrauterine losses and considerable pre and post-surgical mortalities. Therefore, most information concerning the outcome of newborns with TAC is available from pediatric series only. Our current study is the largest cohort of exclusively prenatally diagnosed TAC with a larger number of survivors and significantly longer follow-up period with known surgical treatment and postsurgical health status and therefore may improve the quality of prenatal counselling of affected couples.

Anomalous migration of neural crest cells through the branchial arch vessels during cardiogenesis leads to an incomplete septation (persistence) of the truncus arteriosus (the distal portion of the cardiac outflow tract of the embryonic heart tube) into the pulmonary artery and the aorta [5, 7]. Defective separation affects the aortic sac, the ventriculoarterial junction and the outlet [27]. Consequently, the morphologic characteristics of TAC are (1) the common arterial duct itself, (2) a common arterial orifice and 

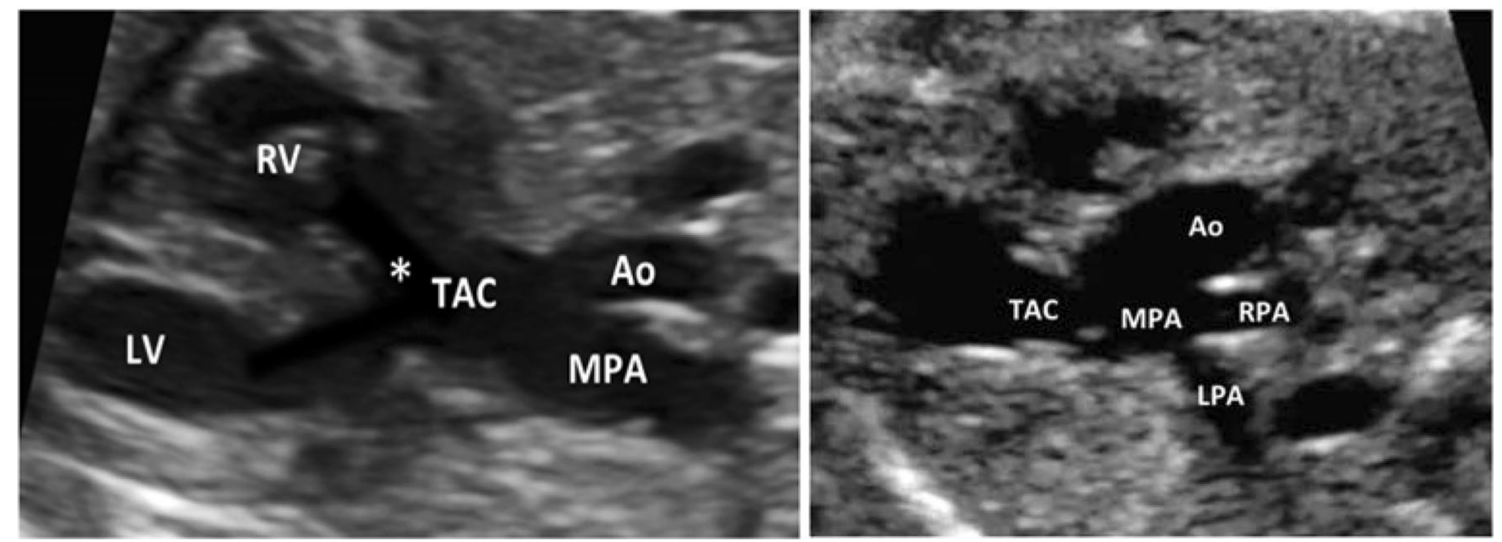

Fig. 4 TAC type 1 with overriding common arterial trunk (TAC). The aorta (Ao) arises from the right side of the common trunk, a short main pulmonary artery (MPA) from the left side of the common trunk. The MPA then divides into the right (RPA) and left pulmonary artery (LPA). (*VSD; $R V$ right ventricle, $L V$ left ventricle)
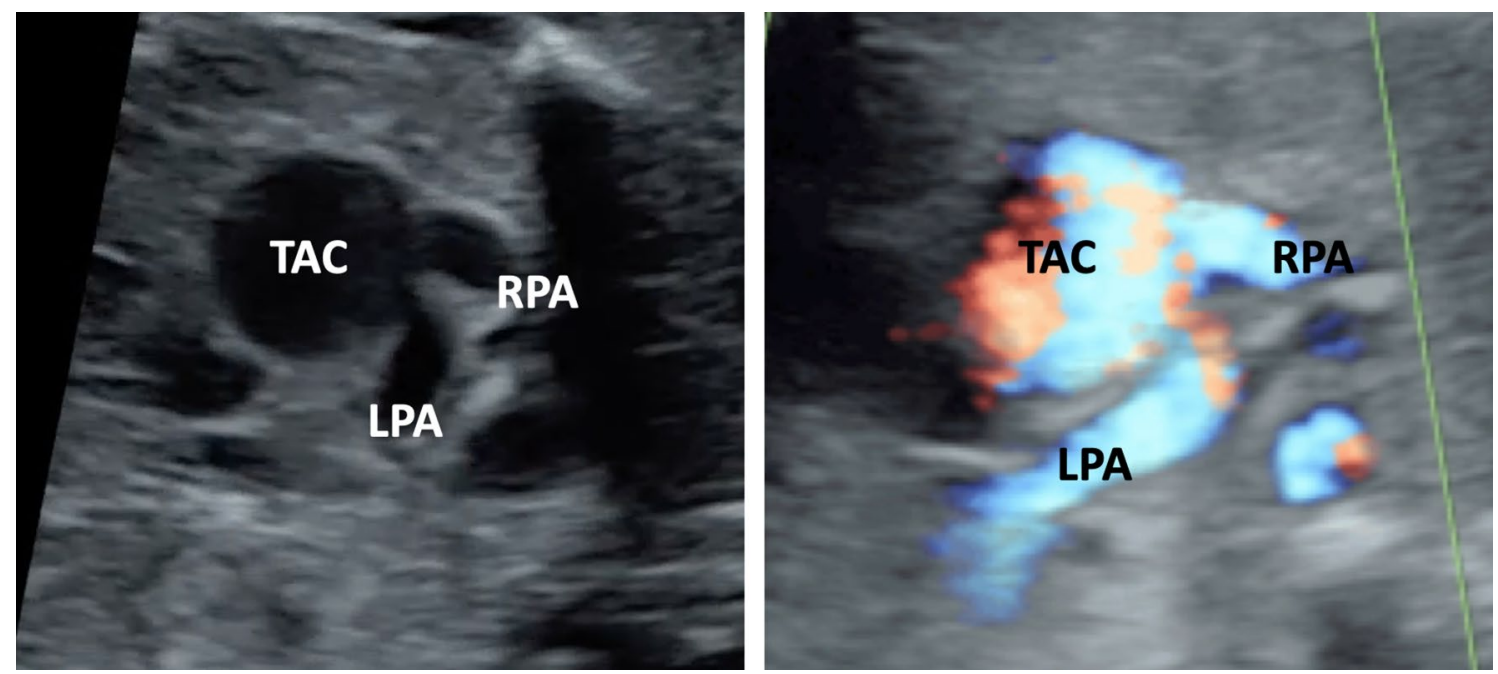

Fig. 5 TAC type 2. Cross-section of the common arterial trunk (TAC) with a separate branching of the right (RPA) and left pulmonary artery (LPA). In this case the branching of both pulmonary arteries is close together

valve and (3) a ventricular septal defect (VSD) in the outflow region $[5,9,27]$. The VSD is usually large and located in the infundibular region, but this defect can also be absent or very small $[9,11,28-31]$. The common arterial valve is often malformed, stenotic or incompetent, the ductus arteriosus is small or absent $[8,11,32]$. In our cohort, a VSD was present in all cases and the common truncal valve was stenotic or insufficient in $23 \%$ of cases.

\section{Classification of TAC and impact on outcome}

The classification by Collet and Edwards [10] describes 4 types of TAC according to the anatomic origin of and spatial relationship between the pulmonary arteries. In type I, a short MPA arises from the left side of the common trunk and divides into the right (RPA) and left pulmonary artery (LPA). In types 2 and 3, both pulmonary arteries arise separately from the posterior part of the common trunk, either close to each other (type 2) or at some distance from each other (type 3 ). In type 4 , the pulmonary arteries arise from the aortic arch or descending aorta as direct branches. Indeed, type 4 is no longer considered a variant of TAC but is rather classified as as pulmonary atresia with VSD and aortopulmonary collateral arteries (PAVSD + MAPCAs).

As aortic arch anomalies including right aortic arch, hypoplastic or interrupted aortic arch, occur quite frequently in TAC [33-37], Van Praagh proposed another classification [11]: Van Praagh's type A1 is similar to Collet and Edwards' 

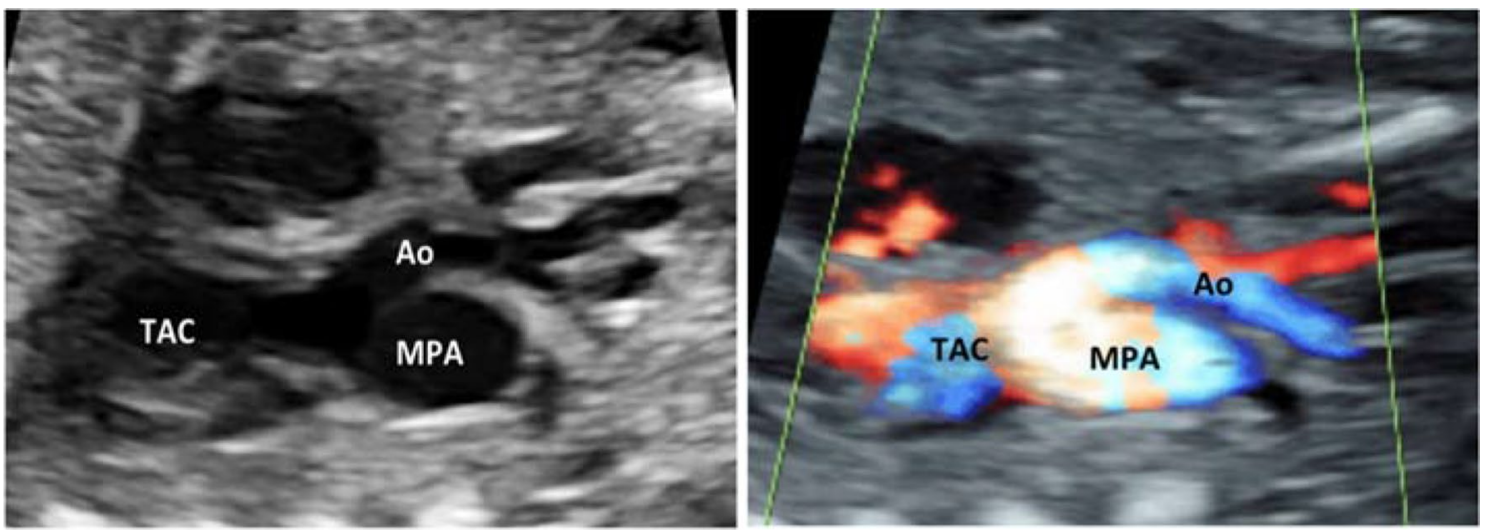

Fig. 6 TAC type A4. The aorta (Ao) and the main pulmonary artery (MPA) arise from the common arterial trunk (TAC). The interrupted aorta divides into the brachiocephalic and left common carotid arteries (interrupted aortic arch type B)

type 1. Van Praagh's type A2 combines Collet and Edwards' type 2 and type 3 . As exact distinction between type A1 and A2 may be difficult even with angiographic evaluation, it has been proposed that both types should be merged into one group [22]. Van Praagh's type A3 describes a unilateral atresia of the pulmonary arteries and pulmonary blood supply through ductal or aortopulmonary collateral vessels. Van Praagh's type A4 refers to aortic arch anomalies and describes TAC with interrupted aortic arch.

In accordance with the Society of Thoracic Surgeons, the Congenital Heart Surgery Database Committee [38] and the European Association for Cardiothoracic Surgery, we grouped our cohort into three TAC types: Type 1 (Collet and Edwards), type 2 (Collet and Edwards) and A4 (Van Praagh).

Data concerning the prevalence of different TAC subtypes in prenatal series are rare. The only published prenatal series with subtype classification by Lee et al. included only 8 cases with confirmed postnatal diagnosis [23]. Due to their small cohort, no reliable information about the prevalence of different subtypes can be obtained. In pediatric series, type 1 is considered the most common type with a prevalence of $47-50 \%$, followed by type 2 in $21 \%$ and type A4 in only $2-12 \%$ of cases $[22,39]$. In accordance, type 1 was the most common type in our cohort. But in contrast, type A4 was much more common in our series with a prevalence of $33 \%$. The significant higher prevalence of type A4 in our prenatal series cannot be explained conclusively, as intrauterine mortality was not higher in fetuses with TAC type A4 compared with the remaining types.

Also, several pediatric series stated that TAC type A4 has a worse outcome compared to the remaining types. Miyamoto et al. stated that overall perioperative mortality in infants with TAC with IAA were indeed decreasing in recent decades, but still high [39]. Perioperative mortality in their own series including 10 infants with TAC type A4 was 50\%. Konstantinovi et al. confirmed the rather worse prognosis of infants with TAC type A4 with a 10-year survival rate of not more than $31 \%$ [33]. In contrast to those pediatric series, we could not confirm the increased postnatal mortality or morbidity in TAC type A4 after prenatal diagnosis: postoperative survival rate at last follow-up did not differ significantly in TAC with (71.3\%) or without IAA (72.7\%). Furthermore, postoperative health status was comparably good in both groups: $80.0 \%$ of infants with TAC with IAA and $78.7 \%$ of infants with TAC without IAA lived without any limitations after surgery. We could state that after prenatal diagnosis of TAC, prognosis is good independently of the subtype, as the subtype did not influence mortality or morbidity in our survivors. If the health status was impaired postnatally than exclusively, it was because of additional major non-cardiac or chromosomal anomalies.

\section{Accuracy of prenatal diagnosis and impact on Outcome}

Precise prenatal diagnosis of TAC can be achieved in the majority of fetuses. Previously published studies report on overall accuracy of prenatal diagnosis between $71 \%$ [23] and $87 \%[24,40]$ (Table 2). Our study confirms that TAC can be diagnosed prenatally with high accuracy. The correct diagnosis of TAC was made in $87 \%$, but diagnosis was usually not made prior to 21 weeks of gestation, presumably due to a predominantly normal looking four-chamber view that conceals this defect at basic cardiac screening. Reduced visibility at echocardiography in very early or late gestational age and additional maternal obesity were negative factors contributing to incorrect diagnosis: in our three cases with incorrect diagnosis, two obese patients were initially referred to our institution for initial echocardiography not before 34 and 37 weeks of gestation, respectively. The third patient was referred for echocardiography only once at early 18 weeks of gestation. Correct subtyping of TAC types 1,2 or A4 could 
Table 2 Meta-analysis of the current and previously published series

\begin{tabular}{|c|c|c|c|c|c|c|}
\hline Author & Current study & Swanson [26] & Lee [23] & Volpe [21] & Duke [24] & Gomez [25] \\
\hline Included cases $(n=)$ & 34 & 43 & 12 & 23 & 17 & 10 \\
\hline Diagnosis pre or postnatally & Pre & Pre + post & Pre & Pre & Pre & Pre \\
\hline $\mathrm{TOP}(n=)$ & $14(41 \%)$ & $17(40 \%)$ & $4(33 \%)$ & $8(35 \%)$ & $4(24 \%)$ & $9(90 \%)$ \\
\hline $\operatorname{IUFD}(n=)$ & $1(2.9 \%)$ & $2(4.7 \%)$ & 0 & $29 \%$ & 0 & 0 \\
\hline Life Birth $(n=)$ & $19(55.8 \%)$ & $24(56 \%)$ & $8(66 \%)$ & $13(57 \%)$ & $13(76.5 \%)$ & $1(10 \%)$ \\
\hline $\mathrm{NND} / \mathrm{CHD}(n=)$ & $5(14.8 \%)$ & $8(18.6 \%)$ & $2(17 \%)$ & $5(22 \%)$ & 8 & - \\
\hline Overall Survival $(n=)$ & $14 / 34(41 \%)$ & $16 / 43(37 \%)$ & $6 / 12(50 \%)$ & $8 / 23(35 \%)$ & $5 / 17(29.4)$ & $1 / 10(10 \%)$ \\
\hline Intention to treat survival $(n=)$ & $14 / 20(70 \%)$ & $16 / 26(62 \%)$ & $6 / 8(75 \%)$ & $8 / 15(53 \%)$ & $5 / 12(42 \%)$ & $1 / 1(100 \%)$ \\
\hline Microdeletion 22q11.2 $(n=)$ & $6 / 34(17.6 \%)$ & $5 / 17(29 \%)$ & 0 & $6 / 19(32 \%)$ & 0 & $1 / 10(10 \%)$ \\
\hline Accuracy of prenatal diagnosis & $87.5 \%$ & $79 \%$ & $71 \%$ & $96 \%$ & $87 \%$ & $66.7 \%$ \\
\hline $\begin{array}{l}\text { Peri or post-surgical mortality } \\
\qquad(n=)\end{array}$ & $5 / 19(26 \%)$ & $4 / 17(24 \%)$ & $2 / 8(25 \%)$ & $2 / 8(25 \%)$ & $2 / 8(25 \%)$ & No data \\
\hline Major associated & $74 \%$ & & & & & \\
\hline Anomalies & $\begin{array}{l}38 \% \text { chromos } \\
9 \% \text { cardiac } \\
59 \% \text { extra-cardiac }\end{array}$ & No data & $\begin{array}{l}50 \% \text { cardiac } \\
17 \% \text { extra-cardiac }\end{array}$ & $\begin{array}{l}35 \% \text { cardiac } \\
43 \% \text { extra-cardiac }\end{array}$ & No data & $\begin{array}{l}40 \% \text { chrom } \\
27 \% \text { extra-cardiac }\end{array}$ \\
\hline TAC type & $\begin{array}{l}38 \% \text { type } 1 \\
29 \% \text { type } 2 \\
33 \% \text { type } \mathrm{A} 4\end{array}$ & No data & $\begin{array}{l}50 \% \text { type } 1 \\
42 \% \text { type } 2 \\
8 \% \text { type } \\
\text { A4 }\end{array}$ & No data & No data & No data \\
\hline Surgery & $\begin{array}{l}n=14 \\
13 \text { complete repair } \\
1 \text { awaiting repair }\end{array}$ & No data & No data & $\begin{array}{l}n=8 \\
6 \text { complete repair } \\
2 \text { palliative treatm }\end{array}$ & $\begin{array}{l}n=8 \\
7 \text { repair } \\
1 \text { palliative }\end{array}$ & No data \\
\hline Follow-up (months) & 42 & No data & No data & 10 & 41 & 10 \\
\hline
\end{tabular}

be achieved in more than $90 \%$ in our cohort. Despite consistent improvement in fetal echocardiography during the last decades, there was no tendency towards an earlier diagnosis during the 8-year study period in our cohort.

The importance of an accurate prenatal diagnosis in counselling parents with regard to prognosis and in predicting the type of postnatal surgical approach is obvious. Swanson et al. showed that infants with prenatal diagnosis of TAC had significantly earlier surgical intervention than infants with postnatal diagnosis [26]. Early surgical intervention might decrease mortality and morbidity as it prevents the long-term sequelae of pulmonary over-circulation and heart failure $[17,18]$. In addition, prenatal diagnosis allows for optimized planning of delivery and postnatal surgical treatment [26].

\section{Additional anomalies and impact on prognosis}

In our cohort, the prognosis of fetuses with TAC mainly depended on the severity of additional extra-cardiac and chromosomal anomalies rather than on the cardiac defect itself. Pediatric series reported on a high prevalence of additional cardiac anomalies including absence of the ductus arteriosus in $50 \%$ of cases and coronary artery anomalies in more than a third of cases [34-36, 41]. In our cohort, additional major cardiac anomalies were rarely seen in only $9 \%$ of cases. As the precise assessment of coronary anomalies is extremely challenging in prenatal situation, those anomalies may escape prenatal diagnosis in many cases.

In contrast, chromosomal and extra-cardiac anomalies occurred in a significant proportion of our fetuses with a prevalence of $38.2 \%$ and $58.8 \%$, respectively. Only $26 \%$ of our fetuses had isolated TAC. This is in accordance with current literature, describing additional anomalies in $40-78 \%$, even though in extremely small cohorts only $[21,23,25,42,43]$ (Table 2). Microdeletion 22q11 was the most common chromosomal anomaly with a prevalence of $17.6 \%$ in our cohort and a prevalence of $10-32 \%$ in other series [21, 25, 26, 42, 43]. In contrast, major extra-cardiac anomalies occurred more frequently in our cohort with a prevalence of $58.8 \%$, compared to $17-43 \%$ in other series $[21,23,25]$. This discrepancy might either be explained by the extremely small cohorts in all other prenatal series, or those series included no data on the presence and severity of additional anomalies, type of surgery or health status at follow-up examinations [21, 23-26]. As comparison with other prenatal series is hardly possible, larger series would be advantageous to confirm our data, as those anomalies significantly complicate the surgical course, contribute to the postnatal mortality and morbidity and may influence parents' decision to continue or terminate the pregnancy. Although, larger series will be hardly achievable due to the 
rarity of this cardiac anomaly. Certainly, prenatal diagnosis of TAC should trigger a meticulous search for additional anomalies and karyotyping should be offered to all parents.

The prevalence of terminations of pregnancies in previously published series varies considerably between $24 \%$ [24], 40\% [26] and 75\% [25]. In our cohort, $41 \%$ of pregnancies were terminated. The low prevalence of TOP in the cohort by Duke et al. [24] might be due to the fact that diagnosis was made rather late in pregnancy and beyond the time period, in which TOP would have been a legal option. In contrast, the high termination rate of $75 \%$ in the cohort by Gomez is astonishing as more than half of the terminated pregnancies had isolated TAC with a presumably good prognosis. In addition, Gomez's series included only 8 cases with an accuracy of prenatal diagnosis of only $67 \%$ [24].

\section{Surgical outcome}

Although TAC is considered a cyanotic congenital heart defect characterized by increased pulmonary blood flow, cyanosis is not a constant feature in neonatal period [12]. However, if TAC is left untreated, the increasing amount of mixed blood perfusing the pulmonary circulation leads to an increase in pulmonary vascular resistance and to cardiac heart failure [44]. Due to pulmonary overflow, $58 \%$ of our neonates needed initial banding of the PA prior to their complete cardiac repair. Among them, 26\% needed additional stenting of the arterial duct.

Single-stage complete cardiac repair was performed in $78 \%$ of our infants, predominantly within their first weeks of life. Among them, half of those infants needed additional reconstruction of their hypo-plastic or interrupted aortic arch. As 14\% of infants with TAC type 1 suffered from progressive cyanosis after conduit insertion due to recurrent conduitstenoses, those infants needed to undergo additional Blalock-Taussig shunting and subsequent Glenn anastomosis.

In contrast to current literature, postoperative health status among our survivors was either excellent in $78 \%$ of infants or significantly impaired in $22 \%$. All individual limitations in health status could exclusively be attributed to additional extra-cardiac or genetic anomalies, e.g. dysphagia and impaired hearing due to severe retrognathia.

Surgical re-interventions after cardiac repair were common during follow-up. In our cohort, $46.2 \%$ of all infants had to undergo 2-6 re-interventions (mean 3.3). Unfortunately, no data on prevalence or frequency of re-interventions were included in other prenatal series, but postnatal pediatric series confirm the high prevalence of re-interventions of $75 \%$ during 10-year follow-up [45].

In conclusion, the prognosis and postoperative health status are excellent in absence of severe extra-cardiac or genetic anomalies. The prognosis is good, independently of the type of TAC, the presence of additional aortic arch anomalies and the competence of the common truncal valve, but the prevalence of repeated interventions due to recurrent stenoses is high.

\section{Meta-analysis of literature}

\section{Limitations}

Our study also has a number of limitations. Although our series is one of the largest cohorts with exclusively prenatal cases with the longest follow-up period, the number of newborns who underwent surgery is still small due to the rarity of the cardiac defect itself and the high pre- and postnatal loss rates. The size of our cohort did not allow for identifying any additional predictors of outcome. Although median follow-up was 42 months in our cohort, no data on long-term outcome could be achieved so far. A further limitation is its retrospective design, that limits the assessment of detailed spatial relationship of some cardiac strutures.

Author contributions AJS: Manuscript writing, data analysis, data collection, project development. BC: Project development, manuscript writing/editing. GA: Manuscript editing, GU: Manuscript editing, HU: Manuscript editing, BJ: Manuscript editing, BK: Manuscript editing, GI: Project development, manuscript writing/editing, data analysis.

Funding Open Access funding enabled and organized by Projekt DEAL.

\section{Declarations}

Conflict of interest The authors declare that there is no conflict of interest.

Ethical approval The institutional review boards of the centers included in the study do not require formal approval for retrospective archives studies. Therefore, ethical approval was not sought.

Informed Consent Due to the retrospective observational design of the study, no informed consent was necessary.

Open Access This article is licensed under a Creative Commons Attribution 4.0 International License, which permits use, sharing, adaptation, distribution and reproduction in any medium or format, as long as you give appropriate credit to the original author(s) and the source, provide a link to the Creative Commons licence, and indicate if changes were made. The images or other third party material in this article are included in the article's Creative Commons licence, unless indicated otherwise in a credit line to the material. If material is not included in the article's Creative Commons licence and your intended use is not permitted by statutory regulation or exceeds the permitted use, you will need to obtain permission directly from the copyright holder. To view a copy of this licence, visit http://creativecommons.org/licenses/by/4.0/. 


\section{References}

1. Ferencz C, Rubin JD, Loffredo CA, Magee CM (1993) The epidemiology of congenital heart disease The Baltimore-Washington Infant Study (1981-1989), in: Perspectives in Pediatric Cardiology. Futura Publishing Co. Inc, NY

2. Reller MD, Strickland MJ, Riehle-Colarusso T, Mahle WT, Correa A (2008) Prevalence of congenital heart defects in metropolitan Atlanta, 1998-2005. J Pediatr 153:807-813

3. Hoffman JI, Kaplan S (2002) The incidence of congenital heart disease. J Am Col Cardiol 39:1890-1900

4. Ferencz C, Rubin JD, Mc Carter RJ, Clark EB (1990) Maternal diabetes and cardiovascular malformations: predominance of double outlet right ventricle and truncusarteriosus. Teratology 41:319-326

5. Gotsch F, Romero R, Espinoza J, Kusanovic JP, Erez O, Hassan S, Yeo L (2010) Prenatal diagnosis of truncusarteriosus using multiplanar display in 4D ultrasonography. J MaternFetal Neonatal Med 23:297-307

6. Crupi G, Macartney FJ, Anderson RH (1977) Persistent truncusarteriosus. A study of 66 autopsy cases with special reference to definition and morphogenesis. Am J Cardiol 40:569-578

7. Webb S, Qayyum SR, Anderson RH, Lamers WH, Richardson MK (2003) Septation and separation within the outflow tract of the developing heart. J Anat 202:327-342

8. Fuglestad SJ, Puga FJ, Danielson GK, Edwards WD (1988) Surgical pathology of the truncal valve: a study of 12 cases. Am J CardiovascPathol 2:39-47

9. Jacobs ML (2000) Congenital heart surgery nomenclature and database project: truncusarteriosus. Ann Thoracic Surg 69:50-55

10. Collett RW, Edwards JE (1949) Persistent truncusarteriosus; a classification according to anatomic types. SurgClin North Am 29:1245

11. Van Praagh R, Van Praagh S (1965) The anatomy of common aorticopulmonary trunk (truncusarteriosuscommunis) and its embryologic implications. A study of 57 necropsy cases. Am J Cardiol 16(7):406

12. Grifka RG (1999) Cyanotic congenital heart disease with increased pulmonary blood flow. PediatrClin North Am 46:405-425

13. Imamura M, Drummond-Webb JJ, Sarris GE, Mee RB (1999) Improving early and intermediate results oftruncusarteriosus repair: a new technique of truncal valve repair. Ann ThoracSurg 67:1142-1146

14. Lacour-Gayet F, Serraf A, Komiya T, Sousa-Uva M, Bruniaux J, Touchot A, Roux D, Neuville P, Planche C (1996) Truncusarteriosus repair: influence of techniques of right ventricular outflow tract reconstruction. J ThoracCardiovascSurg 111:849-856

15. Pearl JM, Laks H, Drinkwater DC Jr, Milgalter E, Orrin AC, Giacobetti F, George B, Williams R (1991) Repair of truncusarteriosus in infancy. Ann ThoracSurg 52:780-786

16. Rajasinghe HA, McElhinney DB, Reddy VM, Mora BN, Hanley FL (1997) Long-term follow-up of truncusarteriosus repaired in infancy: a twenty-year experience. J ThoracCardiovascSurg 113:869-878

17. Rodefeld MD, Hanley FL (2002) Neonatal truncusarteriosus repair: surgical techniques and clinical management. SeminThoracCardiovascSurgPediatr Card Surg Ann 5:212-217

18. Shrivastava S (2000) Timing of surgery/catheter intervention in common congenital cardiac defects. Indian J Pediatr 67:2-6

19. Yagel S, Cohen SM, Achiron R (2001) Examination of the fetal heart by five short-axis views: a proposed screening method for comprehensive cardiac evaluation. Ultrasound ObstetGynecol 17:367-369
20. Carvalho JS, Ho SY, Shinebourne EA (2005) Sequential segmental analysis in complex fetal cardiac abnormalities: a logical approach to diagnosis. Ultrasound ObstetGynecol 26:105-111

21. Volpe P, Paladini D, Marasini M, Buonadonna AL, Russo MG, Caruso G, Marzullo A, Vassallo M, Martinelli P, Gentile M (2003) Common arterial trunk in the fetus: characteristics, associations, and outcome in a multicentre series of 23 cases. Heart 89:1437-1441

22. Calder L, Van Praagh R, Van Praagh S, Sears WP, Corwin R, Levy A, Keith JD, Paul MH (1996) Truncusarteriosuscommunis. Clinical, angiographic and pathologic findings in 100 patients. Am Heart J 92:23-38

23. Lee MY, Won HS, Lee BS, Kim EAR, Kim YH, Park JJ, Yun TJ (2013) Prenatal diagnosis of common arterial trunk: a singlecenter's experience. FetalDiagn Therapy 34:152-157

24. Duke C, Sharland GK, Jones AM, Simpson JM (2001) Echocardiographic features and outcome of truncusarteriosus diagnosed during fetal life. Am J Cardiol 88:1379-1384

25. Gomez O, Bennasar SI, Crispi F, Masoller N, Marimon E, Bartrons J, Gratacos E, Martinez MM (2016) Accuracy of fetal echocardiography in the differential diagnosis betweeentruncusarteriosus and pulmonary atresia with ventricular septal defect. Fetal DiagnTher 39:90-99

26. Swanson TM, Tierney ESS, Tworetzky W, Pigula F, McElhinney DB (2009) Truncusarteriosus: diagnostic accuracy, outcomes, and impact of prenatal diagnosis. PediatrCardiol 30:256-261

27. Bartelings MM, Gittenberger-de Groot AC (1991) Morphogenetic considerations on congenital malformations of the outflow tract. Part 1: Common arterial trunk and tetralogy of Fallot. Int J Cardiol 32:213-230

28. Carr I, Bharati S, Kusnoor VS, Lev M (1979) Truncusarteriosuscommunis with intact ventricular septum. Br Heart J 42:97-102

29. Murdison KA, McLean DA, Carpenter B, Duncan WJ (1996) Truncusarteriosuscommunis associated with mitral valve and left ventricular hypoplasia without ventricular septal defect: unique combination. PediatrCardiol 17:322-326

30. Van Praagh R (1987) Truncusarteriosus: what is it really and how should it be classified? Eur J CardiothoracSurg 1:65-70

31. Ozkutlu S, Ayabakan C, Alehan D (2002) Truncusarteriosus with a very small ventricular septal defect diagnosed by echocardiography. PediatrCardiol 23:244-245

32. Mello DM, McElhinney DB, Parry AJ, Silverman NH, Hanley FL (1997) Truncusarteriosus with patent ductusarteriosus and normal aortic arch. Ann ThoracSurg 64:1808-1810

33. Konstantinov IE, Karamlou T, Blackstone EH, Mosca RS, Lofland GK, Caldarone A, Williams WG, Mackie AS, McCrindle BW (2006) Truncusarteriosus associated with interrupted aortic arch in 50 neonates: a Congenital Heart Surgeons Society study. Ann ThoracSurg 81:214

34. Butto F, Lucas RV Jr, Edwards JE (1986) Persistent truncusarteriosus: pathologic anatomy in 54 cases. PediatrCardiol 7:95

35. Marcelletti C, McGoon DC, Danielson GK, Wallace RB, Mair DD (1977) Early and late results of surgical repair of truncusarteriosus. Circulation 55:636

36. Nath PH, Zollikofer C, Castaneda-Zuniga W, Formanek A, Amplatz K (1980) Persistent truncusarteriosis associated with interruption of the aortic arch. Br J Radiol 53:853

37. Mair DD, Ritter DG, Davis GD, Wallace RB, Danielson GK, McGoon DC (1974) Selection of patients with truncusarteriosus for surgical correction; anatomic and hemodynamic considerations. Circulation 49:144

38. Jacobs ML (2000) Congenital heart surgery nomenclature and database project: truncusarteriosus. Ann ThoracSurg 69:50-55

39. Miyamoto T, Sinzobahamvya N, Kumpikaite D, Asfour B, Photiadis J, Brecher AM, Urban AE (2005) Repair of truncusarteriosus 
and aortic arch interruption: outcome analysis. Ann ThoracSurg 79:2077-2082

40. Tometzki AJ, Suda K, Kohl T, Kovalchin JP, Silverman NH (1999) Accuracy of prenatal echocardiographic diagnosis and prognosis of fetuses with conotruncal anomalies. J Am CollCardiol 33:1696-1701

41. Sharland G (2000) Common arterial trunk. In: Allan LD, Hornberger LK, Sharland GK (eds) Textbook of Fetal Cardiology. Greenwich Medical Media, London

42. Machlitt A, Tennstedt C, Körner H, Bommer C, Chaoui R (2002) Prenatal diagnosis of 22q11 microdeletion in an early second-trimester fetus with conotruncal anomaly presenting with increased nuchal translucency and bilateral intracardiac echogenic foci. Ultrasound ObstetGynecol 19:510-513

43. Boudjemline Y, Fermont L, Le Bidois J, Lyonnet S, Sidi D, Bonnet D (2001) Prevalence of 22q11 deletion in fetus with conotruncal cardiac defects: a 6-year prospective study. J Pediatr 138:520-524

44. Westmoreland D (1999) Critical congenital cardiac defects in the newborn. J Perinat Neonatal Nurs 12:67-8744

45. Alfieris GM, Swartz MF (2016) The initial glimpse at long-term outcomes following the repair of truncusarteriosus. SeminThoracCardiovascSurg 28:512-513

Publisher's Note Springer Nature remains neutral with regard to jurisdictional claims in published maps and institutional affiliations.

\section{Authors and Affiliations}

\section{J. S. Abel ${ }^{1} \cdot$ C. Berg ${ }^{1,2} \cdot$ A. Geipel ${ }^{2} \cdot$ U. Gembruch ${ }^{2} \cdot$ U. Herberg ${ }^{3} \cdot$ J. Breuer $^{3} \cdot$ K. Brockmeier $^{4} \cdot$ I. Gottschalk $^{1}$}

1 Division of Prenatal Medicine, Department of Obstetrics and Gynecology, University of Cologne, Kerpenerstr. 34, 50931 Cologne, Germany

2 Department of Obstetrics and Prenatal Medicine, University of Bonn, Bonn, Germany
3 Department of Pediatric Cardiology, University of Bonn, Bonn, Germany

4 Department of Pediatric Cardiology, University of Cologne, Cologne, Germany 